\title{
SUBSÍdIOS PARA A PROTEÇÃO DE ÁREAS ÚMIDAS DA BACIA DO RIO XINGU (MATO GROSSO, BRASIL) ${ }^{1}$
}

\author{
Rosely Alvim Sanches ${ }^{2}$, Amintas Nazareth Rossete ${ }^{3}$, Ana Carolina Pinto Rezende ${ }^{4}$, Heber Queiroz Alves ${ }^{4}$ e \\ André Villas-Bôas ${ }^{5}$
}

\begin{abstract}
RESUMO - O rio Suiá-Miçu é um importante tributário do rio Xingu, e sua bacia hidrográfica (BHSM), situada no planalto do Parecis, Estado de Mato Grosso, abrange 2,36 milhões de hectares. A BHSM contempla Formações Pioneiras, Cerrados e a Floresta Estacional Perenifólia, cuja composição de espécies é consequência da variabilidade de chuvas e do clima estacional. O objetivo deste trabalho foi caracterizar as áreas úmidas da BHSM e sua importância para a preservação ambiental. O mapeamento da BHSM foi realizado a partir do georreferenciamento de imagens do satélite CBERS-2 (2006), que resultou em um mosaico RGB234 com 20 m de resolução. Esse mosaico permitiu o mapeamento de todas as drenagens da BHSM e, assim, a definição da planície de inundação, complementada pelo cruzamento dos mapas de hidrografia e geomorfologia e trabalhos de campo. Os resultados indicaram mais de 192 mil hectares de área de inundação, dos quais 13\% foram desmatados para usos agropecuários. As áreas úmidas da BHSM têm papel importante no suprimento de água durante as estações secas. São compostas de hábitats fluviolacustres e de uma diversidade de vegetação que abarca os campos úmidos, a floresta inundável e as veredas (dominadas pelo buriti Mauritia flexuosa). Apesar de no Brasil existirem leis ambientais para proteção de cursos d'água e das áreas marginais, sua implementação e monitoramento são necessários, dada a fragilidade de ecossistemas presentes na planície de inundação, como no caso da BHSM. Recomendam-se mais pesquisas científicas sobre esses ecossistemas para apoiar as tomadas de decisão na proteção das áreas úmidas no Brasil.
\end{abstract}

Palavras-chave: Floresta ciliar, Áreas Úmidas e Rio Suiá-Miçu.

\section{SUBSIDIES FOR THE WETLANDS PROTECTION OF XINGU RIVER BASIN (STATE OF MATO GROSSO, BRAZIL)}

\begin{abstract}
The Suiá-Miçu Basin (BHSM) is an important Xingu River tributary, in the Amazon Basin, comprised of 2.36 millions hectare of ha in the Parecis Plateau, State of Mato Grosso. It encompasses the savannah, the tropical rainforest and the seasonal evergreen forest, whose composition of species reflect the rainfall and the high seasonality. The objective of this work was to characterize the BHSM floodplain areas, and their role for the environmental preservation. The georeferencing of CBERS-2 satellite images (2006) resulted in a RGB234 mosaic with 20 meters of resolution for mapping BHSM drainages. This mosaic allowed to map all drains of the BHSM, therefore, defining the flooded areas, complemented by crossing the hydrography and geomorphological maps as well as the field works. The results point out an area with more than 192,000 hectares, of which approximately $13 \%$ were deforested mainly for agricultural uses. The BHSM wetland areas have an important role in supplying water during the dry seasons. They are composed of fluvio-lacustrine habitats and vegetation diversity as native grassland, flooded forests and veredas ( swamp Mauritia flexuosa dominant palms). In Brazil, despite having environmental legislation to fully protect the river and its marginal lands, it is of prime importance to monitor these areas, due to ecosystems fragility found in the BHSM floodplain. Therefore, we recommend more scientifically studies on these ecosystems to carry out decision-making on Brazilian wetland protection areas.
\end{abstract}

Keywords: Riparian forest, Wetlands and Suiá-Miçu river.

\footnotetext{
${ }^{1}$ Recebido em 19.08.2010 e aceito para publicação em 19.04.2012.

${ }^{2}$ Programa de Pós-Graduação em Ambiente e Sociedade pelo Núcleo de Estudos e Pesquisas Ambientais/UNICAMP. E-mail: $<$ rosanches@zipmail.com.br>.

${ }^{3}$ Universidade do Estado de Mato Grosso, UNEMAT, Brasil. E-mail: <amnrote@uol.com.br>.

${ }^{4}$ Instituto Socioambiental - ISA, Brasil. E-mail: <anacarolina.rezende@ gmail.com> e <heber@ socioambiental.org>.

${ }^{5}$ Secretário Executivo e Coordenador do Programa Xingu, do Instituto Socioambiental. E-mail: <vboas@ socioambiental.org>.
} 


\section{INTRODUÇÃO}

Estudos da biodiversidade amazônica abrangeram, em sua maioria, as áreas de estuários próximos à cidade de Altamira (PRANCE, 1979; CAMPBELL et al., 1986; ALMEIDA et al., 2004), Manaus e Belém. A grande lacuna de conhecimentos científicos é referente à parte sul da Amazônia, especialmente os altos cursos dos seus tributários como o rio Xingu, no Mato Grosso (CAPOBIANCO et al., 2001; KUNZ et al., 2010). Nessa região, uma característica marcante é a presença das planícies de inundação que em épocas de cheias não permitem distinguir o canal principal, conforme Gregor (1980).

As planícies de inundação podem ser definidas como áreas inundadas sazonalmente pelo transbordamento lateral de rios ou lagos, pelas águas das chuvas ou subterrâneas, consideradas de alta produtividade e valor ecológico (BAYLEY, 1995; GREN, 1995). Na Amazônia, essas planícies abrangem uma superfície de aproximadamente $300.000 \mathrm{~km}^{2}$ (JUNK, 1993). Na bacia do Xingu, no Norte de Mato Grosso, as planícies de inundação ocorrem no baixo curso dos formadores do Xingu, como é o rio Suiá-Miçu, e comportam-se como várzea sazonal (ALMEIDA et al., 2004), pois seu sistema hídrico está submetido ao ciclo anual de enchente e vazante (PRANCE, 1979). Essa dinâmica prove matéria orgânica através do aporte de água dos lagos, dos rios, das chuvas e lençóis subterrâneos, que resultam em ambientes férteis (JOLY et al., 1999). Além disso, devido às características fitossociológicas e dos substratos, essas planícies são constituídas por uma diversidade de ecossistemas, como as florestas inundáveis, as veredas, os campos úmidos, entre outros (RIZZINI, 1992; MARTINS et al., 2008).

Este trabalho teve por objetivos caracterizar e delimitar as áreas úmidas da planície da bacia hidrográfica do rio Suiá-Miçu (BHSM). Essa bacia apresenta alto potencial hídrico para o consumo humano e para a agricultura, de acordo com o relatório do Plano Estadual de Recursos Hídricos do Estado de Mato Grosso (BRASIL, 2007). Além dessa importância, destaca-se a relação intrínseca dos índios Kĩsêdjê com o rio Suiá-Miçu, desde tempos imemoriais (SEEGER, 1981). Os Kĩsêdjê, bem como outros grupos, foram transferidos para o Parque Indígena do Xingu (PIX) na década de 1960, com a política nacional de ocupação, integração e desenvolvimento econômico da Amazônia. Esse grupo indígena representa uma das 16 etnias do Parque Indígena do Xingu (SEEGER, 1981; MENEZES, 1999), cujos territórios tradicionais foram restritos, atualmente, à Terra Indígena Wawi, situada no baixo curso do rio Suiá-Miçu e contígua ao PIX.

Uma das formas de conservar os recursos hídricos e garantir o equilíbrio ambiental e suprimento de água para a população humana está na proteção das áreas úmidas. Entretanto, essas áreas têm sofrido alterações em sua dinâmica devido ao uso intensivo da terra (TURNER, 1991; RICHARDSON, 1994; TOCKNER; STANFORD, 2002). Particularmente, a região das nascentes do Xingu, onde se localiza a BHSM, foi marcada nos últimos 40 anos pelos desmatamentos intensivos devido à abertura de rodovias, à expansão de núcleos urbanos e à implantação de projetos agropecuários (BARROZO, 2008). Até 2007, mais de 5,4 milhões de hectares de florestas e cerrados nessa região foram convertidos em pastagens e monoculturas de soja (SANCHES; VILLAS-BÔAS, 2008). Essa tendência será mantida caso forem concretizados, em um cenário futuro, os projetos e grandes obras governamentais para a Amazônia, como: asfaltamento das BR-163, BR 158, entre outras (LAURENCE et al., 2001; SOARESFILHO et al., 2006; MARTINEZ et al., 2007).

Dadas a importância das áreas úmidas da BHSM para a população local (indígena e não indígena) e as pressões de uso e ocupação nessa região, é necessário identificá-las com o apoio de técnicas de geoprocessamento, para que se possa subsidiar a aplicação das leis de proteção dessas áreas. Embora a legislação ambiental disponha das áreas de preservação permanente (APP), de acordo com a largura do curso d'água, a delimitação da faixa de proteção nos casos de planícies de inundação, como a do rio Suiá-Miçu, é um desafio.

\section{MATERIAL E MÉTODOS}

\section{1. Área de estudo}

A bacia do rio Xingu está situada entre os Estados do Pará e do Mato Grosso e abrange 51,1 milhões de hectares, onde o Xingu é o seu principal curso d'água. No Mato Grosso, onde estão as nascentes desse rio, destaca-se a bacia do rio Suiá-Miçu, importante tributário do rio Xingu. A bacia do rio Suiá-Miçu possui 2,36 milhões de hectares (Figura 1), dos quais $14 \%$ estão situados dentro do PIX e da Terra Indígena Wawi. 


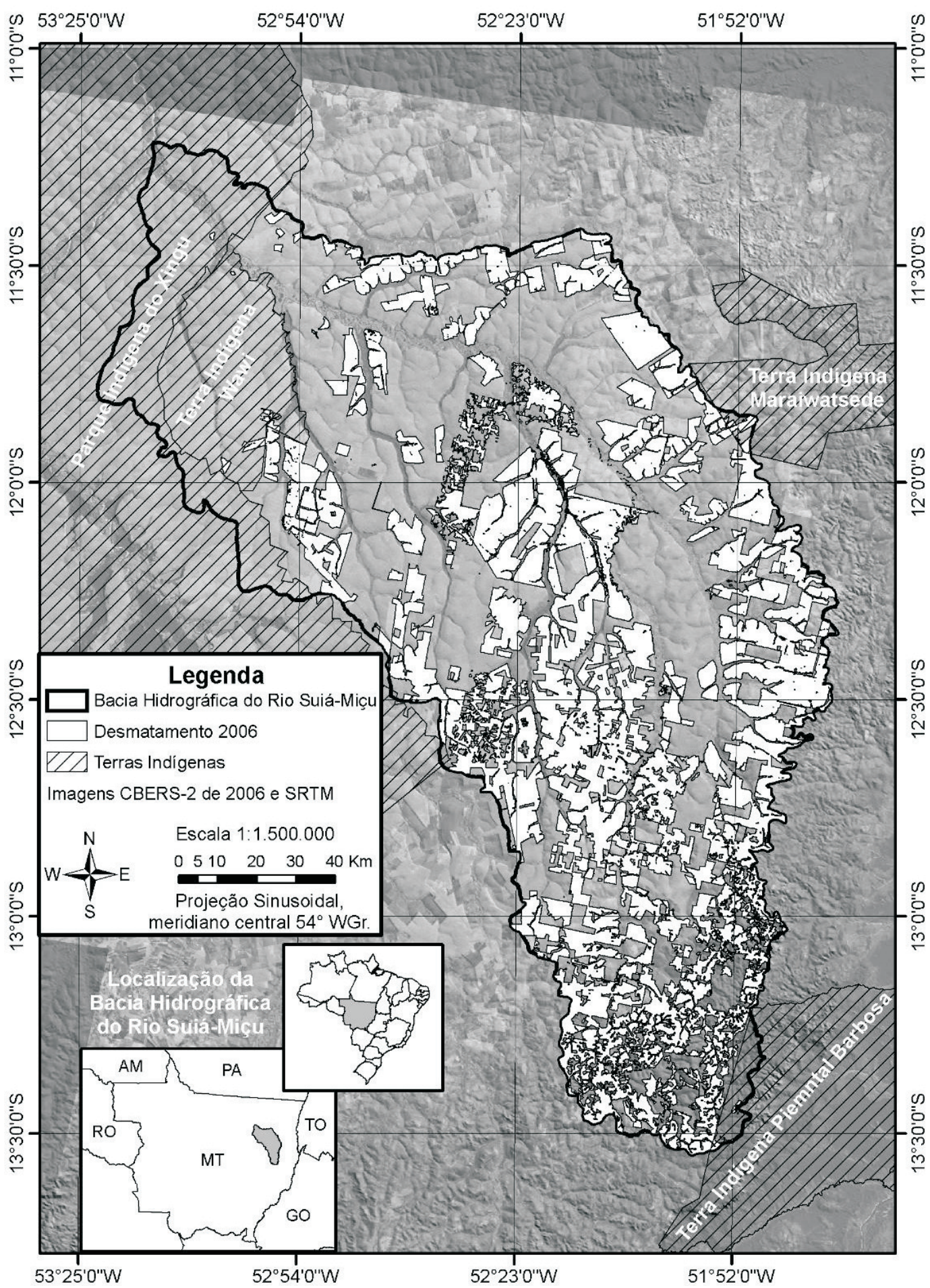

Figura 1 - Localização da bacia hidrográfica do Suiá-Miçu e desmatamentos (até 2006). Figure 1 - Suiá-Miçu Basin localization and deforestation (until 2006). 
A bacia do rio Suiá-Miçu (BHSM) é recoberta pela Floresta Estacional Perenifólia e as cabeceiras dos seus principais formadores (rio Suiazinho, Suiazão e Darro), por fitofisionomias típicas do Cerrado (ASKEW et al., 1970; IVANAUSKAS et al., 2004). Em seu baixo e médio curso, devido ao relevo plano da BHSM, o rio SuiáMiçu forma meandros e lagos que, na época de chuvas, transbordam em diversas áreas da vasta planície (ROSSETE, 2008). Nessa planície, destacam-se das florestas de terra firme diversas fitofisionomias genericamente designadas por floresta de inundação e brejos, segundo a terminologia proposta por Prance (1979). No entanto, elas englobam também vegetação com predominância de buriti (Mauritia flexuosa), denominada vereda (RIZZINI, 1992), que é um ecossistema particular dentro dessas formações.

A partir de intenso processo de ocupação e expansão agropecuária e cultivo da soja, metade da cobertura vegetal nativa da BHSM foi devastada fora das terras indígenas (Figura 1), nos últimos 10 anos (SANCHES; VILLAS-BÔAS, 2008). Esse processo foi marcante na década de 1970, com alta migração de produtores rurais e grandes empresas capitalistas para a região, que implantaram lavouras mecanizadas e extensas áreas para pecuária com subsídios advindos dos incentivos financeiros da Superintendência para o Desenvolvimento da Amazônia SUDAM (LOVEJOY, 2000; MARTINEZ et al., 2007; BARROZO, 2008).

As áreas contidas na BHSM são consideradas pelo povo Kĩsêdjê, da Terra Indígena Wawi, como seu domínio tradicional, que inclui as cabeceiras do rio Suiá-Miçu e seus afluentes (SEEGER, 1981). Os impactos daquele processo de ocupação afetaram diretamente esse povo em razão, principalmente, do assoreamento dos rios, do desmatamento das nascentes e da destruição de diversos recursos vegetais e animais, que são utilizados por eles em seus rituais, bem como a restrição em acessar tais recursos, que ficaram dentro de propriedades rurais e fora da delimitação da terra indígena.

Além da importância cultural para os índios, os rios da BHSM, como o rio Darro e o rio Suiá-Miçu, são utilizados para pesca amadora, turismo e atividades de lazer da população local do Município de Querência e, também, de outras regiões do país. Os produtores rurais de assentamentos também utilizam direta e indiretamente as áreas de inundação, para captação de água, irrigação e pesca, entre outras atividades.

\subsection{Identificação das áreas úmidas}

O mapeamento das áreas úmidas da BHSM foi realizado com base em imagens do Satélite Sino Brasileiro de Recursos Terrestres (CBERS-2), sensor CCD (Câmara Imageadora de Alta Resolução) e resolução espacial de 20 m, órbita/ponto 162/113; 162/114; 162/115; 163/ $113 ; 163 / 114 ; 163 / 115 ; 164 / 113$; e 164/114, com data de passagem entre julho de 2006 e setembro de 2006.

Essas imagens, bandas 2, 3 e 4, em formato digital foram importadas para o software SPRING 4.0, sendo georreferenciadas e unidas para compor o mosaico. No SPRING 4.0 foi gerada uma composição colorida RGB 234, onde foram realizadas operações de realce de contraste (CRÓSTA, 1992; LIU, 2007).

O método utilizado para realizar o mapeamento foi a interpretação visual de imagens, considerandose as diferenças de tonalidade e textura da vegetação. Para resolução de eventuais dúvidas de interpretação, foram utilizadas informações sobre solos, geomorfologia, geologia e vegetação, resultantes do mapeamento do Estado do Mato Grosso produzido pelo Projeto de Desenvolvimento Agroambiental do referido Estado. Esse método, segundo Borges et al. (2009), pode ser aprimorado através do uso de imagens com alta resolução.

Foram realizadas cinco expedições em campo, com duração mínima de 10 dias, em diferentes períodos entre 2003-2007, com o objetivo de caracterizar e identificar as áreas de inundação, os diferentes ambientes e o estado de conservação da planície da BHSM, bem como os padrões de uso da terra e de alteração das paisagens.

A partir dessas informações, foi realizada a delimitação das áreas úmidas da BHSM em laboratório. No alto curso do Suiá-Miçu, os rios possuem leito definido, ao contrário do baixo curso, em que é possível identificar apenas o espelho d'água, que reflete a área de inundação do Suiá-Miçu e seus afluentes. Em seguida foi projetada a faixa de proteção com base na legislação em vigor sobre as Áreas de Preservação Permanente - APP, previstas no Código Florestal (Lei no 4.771, de 15 de setembro de 1965) e na Lei Complementar $n^{\circ} 38$, de 21 de novembro de 1995 (Estado do Mato Grosso). Desse modo, foram adotados para definição de APP os seguintes limites: ao longo dos rios ou qualquer curso d’água, a largura da APP depende da largura do rio, sendo no mínimo de $50 \mathrm{~m}$ para rios com até

Revista Árvore, Viçosa-MG, v.36, n.3, p.489-498, 2012

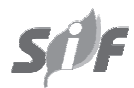


essa largura e no máximo de $500 \mathrm{~m}$ para aqueles com largura igual ou superior a $600 \mathrm{~m}$. A delimitação da APP segue, a partir da faixa marginal, o nível mais alto da água (que é o "nível alcançado por ocasião da cheia sazonal do curso d'água perene ou intermitente", de acordo com o artigo segundo da Resolução CONAMA 303, de 2002). No caso de lagos e lagoas naturais situados em áreas rurais, foi adotada a Lei Complementar $\mathrm{n}^{\circ}$ 38, de 21 de novembro de 1995, do Estado do Mato Grosso, que estabelece a metragem mínima de $100 \mathrm{~m}$ para a APP. No caso de veredas em projeção horizontal, a largura mínima da APPé de $50 \mathrm{~m}$, conforme a legislação, a partir do limite do espaço brejoso e encharcado. No caso específico da planície de inundação da BHSM, considerou-se a largura do espelho da água que, em muitas situações, ultrapassou os $600 \mathrm{~m}$.

\section{RESULTADOS}

Foi mapeada uma área de 192 mil hectares de um total 2,36 milhões de hectares (pouco menos de 10\% da BHSM), que corresponde à faixa identificada como planície de inundação do rio Suiá-Miçu (Figuras 2 e 3 ). Ela compreende o baixo e o médio curso do córrego Wawi, rio das Pacas, rio Paranaíba, córrego Jandaia, rio Darro, rio Suiazão e rio Suiazinho, que correm sobre terreno predominantemente plano (ROSSETE, 2008).

Parte dessa planície de inundação é recoberta por Floresta Estacional Perenifólia Ribeirinha (STEFANELLO et al., 2010), por buritizais, brejos, campos úmidos, entremeadas pelo que se denominam "ilhas de mata". Estas são pequenas áreas de terra firme que se localizam em diferentes locais da planície de inundação. Nos trechos do médio curso dos rios Suiazinho e Suiazão aparecem lagos, lagoas e campos úmidos ao longo dos meandros.

Devido ao regime de cheias e vazantes dos rios ocorre a acumulação de grande quantidade de matéria orgânica que origina solos orgânicos e turfosos (solos hidromórficos, Gleissolo). Essa formação se estabelece ao longo de cursos d'água e ao redor das depressões fechadas que acumulam muita água, formando pântanos e lagoas (ROSSETE, 2008).

Na BHSM é preocupante a expansão do cultivo da soja (MORTON et al., 2006), que vem avançando nos últimos 10 anos, além do uso intensivo, principalmente, pela atividade pecuária (Figura 4). Após o mapeamento da planície de inundação, constatou- se que $13 \%$ de sua área (cerca de 25 mil ha) foi desmatada e alterada para uso agropecuário, conforme demonstrado na Figura 4. Esse dado se contrapõe ao estudo de Maeda et al. (2008), que afirmaram que as vegetações que compõem as áreas de alagamento dos rios "foram de forma geral preservadas", por serem "impróprias" para as atividades agropecuárias.

A partir dos cursos d'água e da área de inundação mapeados na BHSM, estimaram-se 337 mil ha de áreas que são consideradas de preservação permanente (APP) e que, portanto, devem ser protegidas por lei. Considerando que esse resultado é relativo à imagem de satélite obtida em período de seca, pode-se dizer que a área de APP da BHSM é uma estimativa conservadora. Nos períodos de cheia, a largura do espelho da água é maior e, consequentemente, a APP também.

\section{DISCUSSÃO}

As características observadas a partir das incursões ao longo da planície de inundação da BHSM mostram uma riqueza biológica entre os ambientes fluviolacustres, buritizais, campos úmidos e brejos, entremeados pelos ambientes de terra firme. Na literatura, há vasta discussão sobre as terminologias para as diferentes formações vegetais que compõem uma planície aluvial (PRANCE, 1979; MARTINS et al., 2008).

As áreas de inundação, de acordo com as características das espécies, dos solos, a umidade e o ciclo das cheias podem ser classificadas como florestas de inundação periódica e permanente (PRANCE, 1979). A essas formações estão associados os buritizais (em que predomina a palmeira Mauritiaflexuosa), os campos úmidos (em áreas sempre alagadas) e a mata de brejo, ou floresta paludosa (em áreas com solo encharcado) (RIZZINI, 1992).

Para este estudo na BHSM, adotou-se a terminologia empregada por Stefanello et al. (2010): Floresta Estacional Perenifólia Submontana (no interflúvio, área não inundável); Floresta Estacional Perenifólia Ribeirinha (áreas com inundação temporária ou permanente); e Formações Pioneiras com influência fluvial ou lacustre (engloba as comunidades aluviais, desde campo úmido, buritizais e veredas). Kunz et al. (2010) e Stefanello et al. (2010) foram os únicos a realizarem levantamentos fitossociológicos na BHSM e, especificamente, da Floresta Ciliar do Pacas, um formador do rio Suiá-Miçu. De acordo com Stefanello (2008), ocorrem 69 espécies, 


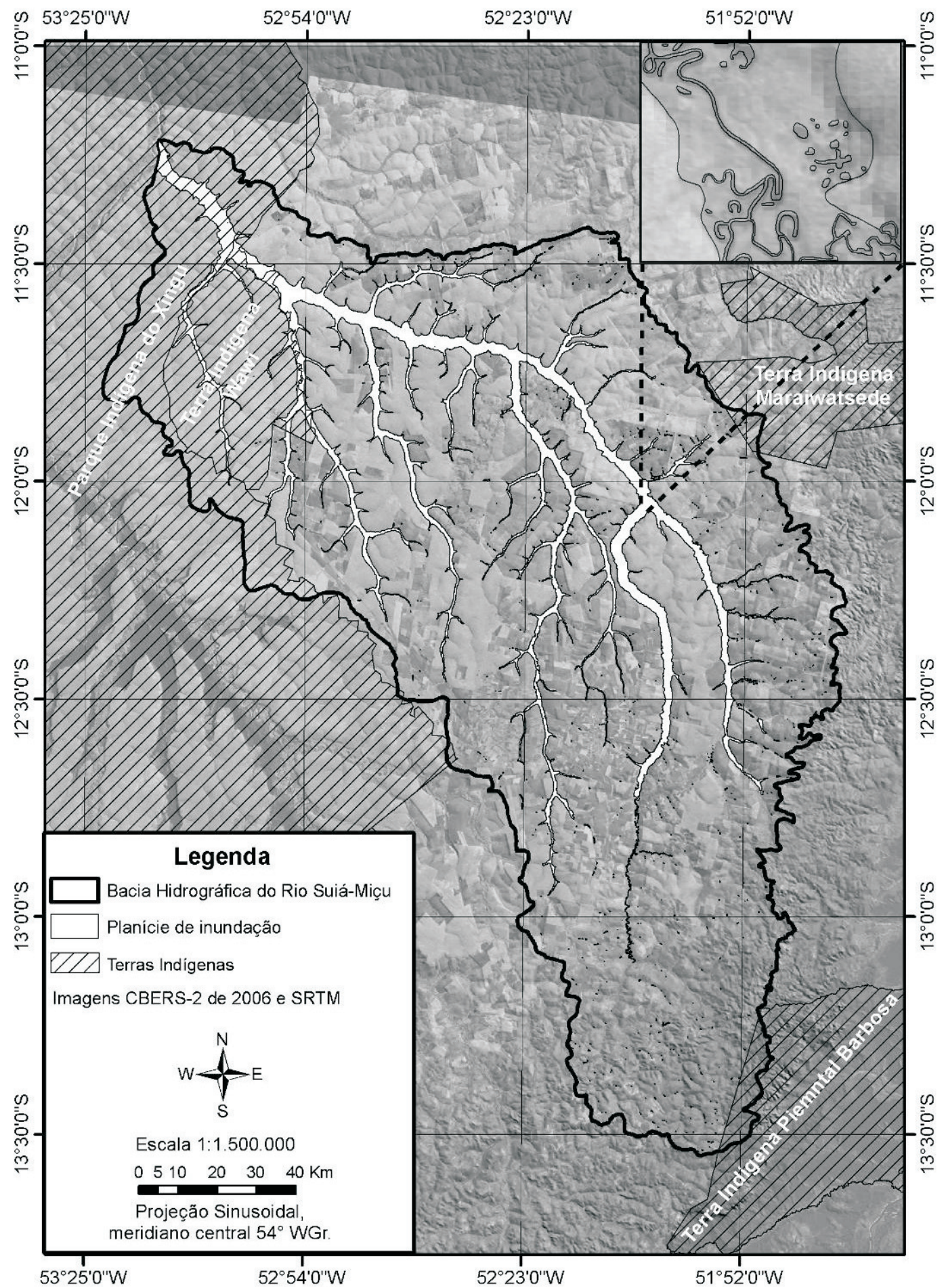

Figura 2 - Detalhe do mapeamento da planície de inundação da bacia do rio Suiá-Miçu.

Figure 2 - Suiá-Miçu basin floodplain areas mapping.

Revista Árvore, Viçosa-MG, v.36, n.3, p.489-498, 2012 
Fonte: ANDRÉ VILLAS-BÔAS/ISA

Source: ANDRÉ VILLAS-BÔAS/ISA.

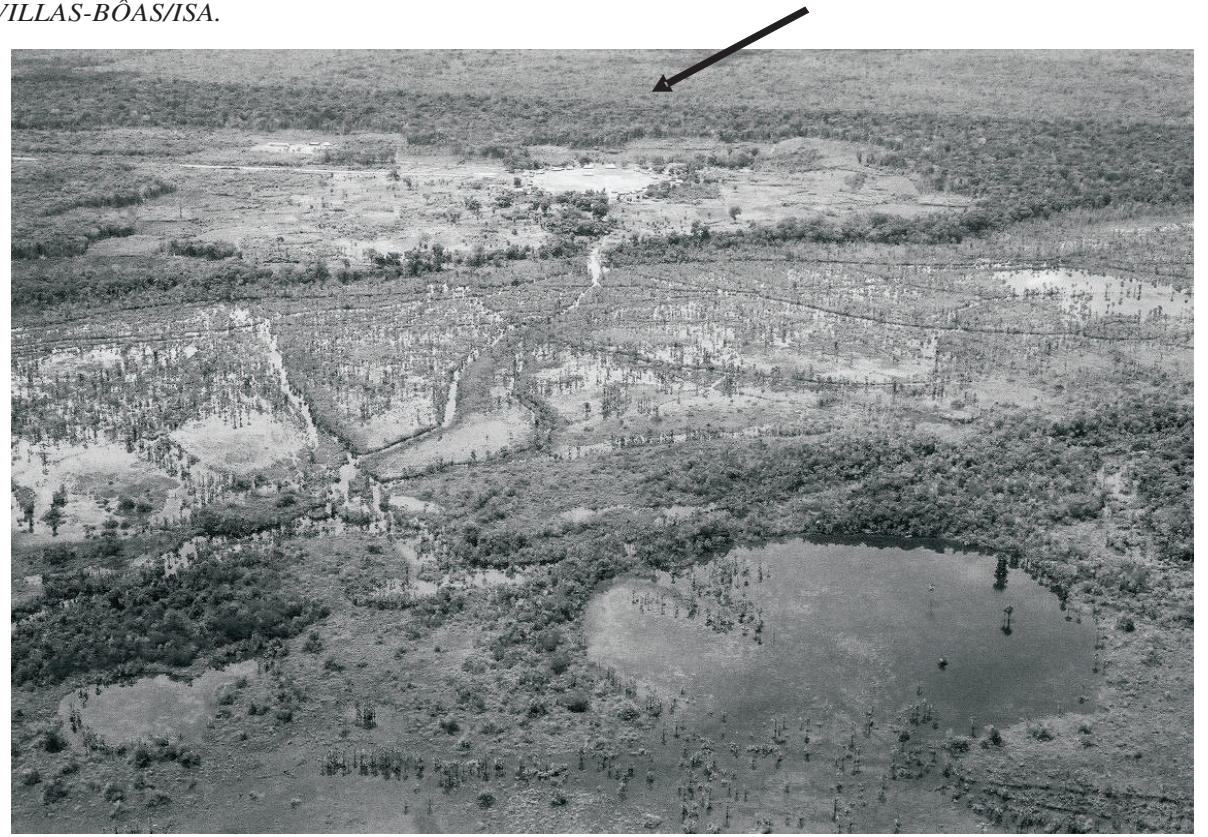

Figura 3 - Vista aérea da planície de inundação do Suiá-Miçu mostrando o rio das Pacas. A seta indica a localização da aldeia do povo Kísêdjê.

Figure 3 -Aerial vision from Suiá-Miçu floodplain showing Pacas River and the Indian village of Kísêdjê (arrows on the background).

Fonte: ANDRÉ VILLAS-BÔAS/ISA.

Source: ANDRÉ VILLAS-BÔAS/ISA.

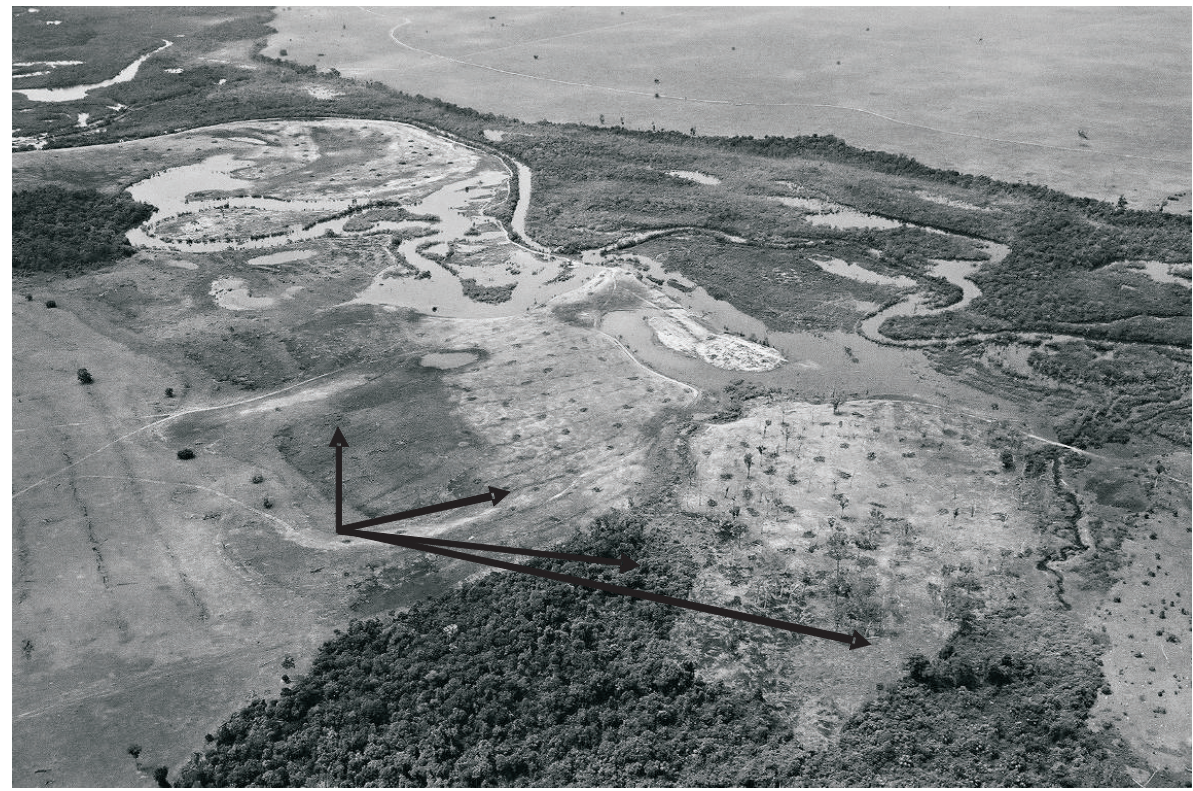

Figura 4 - Setas indicando áreas degradadas em áreas alagadas da bacia do rio Suiá-Miçu por uso agropecuário intensivo. Figure 4-Suiá-Miçu flooded areas degradation by intense farming indicated by arrows. 
11 das quais exclusivas da Floresta Estacional Perenifólia Ribeirinha do rio das Pacas. Esse autor destaca a presença de Ocotea caudata, Jacaranda copaia, Ocotea guianensis e Sloanea eichleri como aquelas de maior importância ecológica e mostra que a diversidade de Shannon é similiar às de outras regiões de várzea da Amazônia.

Outros levantamentos seriam necessários para melhor compreender a diversidade dos ecossistemas em áreas úmidas na BHSM e na Amazônia (MARTINS, 2010). Apesar dos estudos realizados, o futuro da BHSM depende da aplicação e monitoramento das leis brasileiras como disposto nas Áreas de Preservação Permanente (APPs), no Código Florestal (Lei n 4.771, de 15 de setembro de 1965), na Resolução CONAMA n 303 (20 de março de 2002) e leis complementares. Isso se deve ao fato de a planície de inundação ser uma área pedologicamente recente e com sedimentos inconsolidados (ROSSETE, 2008), em que as atividades intensivas de uso do solo acarretam em erosão e assoreamento dos rios, processos esses já identificados na BHSM. Assim, o monitoramento dos processos de poluição, de construção e de operação dos sistemas de captação poderá auxiliar no controle e fiscalização das práticas inadequadas ou ilegais em APP.

Outra forma de proteger as áreas úmidas da BHSM é estabelecer uma zona de preservação dos recursos hídricos, conforme previsto no Zoneamento EcológicoEconômico do Estado (ROSSETE, 2008). Ou, ainda, a criação de uma zona úmida conforme o Decreto 1.905 (16 de fevereiro de 1996), que promulga a Convenção sobre Zonas Úmidas de Importância Internacional, ou Convenção Ramsar (de 1971). Essa Convenção, bem como a Convenção da Biodiversidade de 1992, a Convenção de Washington de 1940 e a Declaração do Rio de Janeiro de 1992, constitui compromisso assumido pelo Brasil, em que as APPS e outros espaços territoriais especialmente protegidos são instrumentos de relevante interesse ambiental e integram o desenvolvimento sustentável, objetivo das presentes e futuras gerações.

Por fim, com o zoneamento da BHSM realizado com a participação da população local pode-se planejar um sistema de monitoramento, fiscalização e gestão das áreas úmidas, que leve em conta o desenvolvimento regional e a melhoria da qualidade de vida da população. Atualmente, apenas existem recomendações gerais de uso e proteção das áreas úmidas, no plano estadual dos recursos hídricos de Mato Grosso (BRASIL, 2007).

\section{CONCLUSÃO}

Este trabalhoé uma primeira aproximação para estimar a planície de inundação e a faixa de proteção, a APP, da BHSM. São necessários considerar outras metodologias em geoprocessamento para definição de áreas alagadas e aprofundar os levantamentos biofísicos em campo. Além disso, devem-se discutir os impactos socioeconômicos que poderiam gerar a aplicação da faixa de APP estimada na BHSM, em consideração ao uso atual agropecuário, à presença de assentamentos e aos demais usos.

Espera-se instigar que novos estudos contribuam para a proteção e preservação da BHSM e que sejam feitas novas investigações sobre as nascentes do Xingu e demais áreas úmidas do Brasil. É urgente a proteção especial dessas áreas na forma da lei, para garantir a integridade física e biológica das bacias hidrográficas.

\section{AGRADECIMENTOS}

Ao povo Kísêdjê, pelo apoio aos trabalhos de campo; às sugestões e críticas de Natália Ivanauskas (Instituto Florestal-SP) e dos revisores; e à Agência dos Estados Unidos para Desenvolvimento Internacional, à Fundação de Amparo à Pesquisa do Estado de Mato Grosso e à Universidade do Estado de Mato Grosso, pelo apoio técnico e financeiro na realização do Projeto Gestão Ambiental e Ordenamento Territorial da Bacia do rio Suiá-Miçu.

\section{REFERÊNCIAS}

ALMEIDA, S. S.; AMARAL, D. D.; SILVA, A. S. L. Análise florística de florestas de Várzea no estuário Amazônico. Acta Amazônica, v.34, n.4, p.513-524, 2004.

ASKEW, G. P. et al. Interrelationships of Soils and Vegetation in the Savanna-Forest Boundary Zone of North-Eastern Mato Grosso. The

Geographical Journal, v.136, n.3, p.370-376, 1970.

BARROZO, J. C. Políticas de colonização: as políticas públicas para Amazônia e o CentroOeste. In: BARROZO, J. C. (Org.). Mato Grosso do sonho à utopia da Terra. Cuiabá: EdUFMT, Carlini \& Caniato Editorial, 2008. p.15-26. 
BAYLEY, P. B. Understanding large river: floodplain ecosystems. BioScience, v.45, n.3, p.153-158, 1995.

BORGES, R. F. et al. Mapeamento de áreas úmidas através de dados de sensoriamento remoto e técnicas de geoprocessamento na Bacia Hidrográfica do Ribeirão Bom Jardim - MG. Disponível em: <http://www.geo.ufv.br/ simposio/simposio/trabalhos/trabalhos_completos/ eixo1/070.pdf> Acesso em: 22 mar.2010.

BRASIL. Ministério do Meio Ambiente e da Amazônia Legal. Consolidação da etapa de diagnóstico dos estudos sobre recursos hídricos no estado de Mato Grosso. Produto 1, RT 1.. Cuiabá: 2007. 173p.

CAMPBELL, D. G.; DALY, D.C.; PRANCE, G. T. Quantitative ecological inventory of terra firme and varzea tropical forest on the Rio Xingu, Brazilian Amazon. Brittonia, v.38, n.4, p.369-393, 1986.

CAPOBIANCO, J. P. R. et al. Biodiversidade na Amazônia Brasileira. São Paulo: Estação Liberdade, 2001. 540p.

CRÓSTA, A. P. Processamento digital de imagens de sensoriamento remoto. Campinas: IG/UNICAMP, 1992. 170p.

GREN, I. The value of investing in wetlands for nitrogen abatement. European Review of Agricultural Economics, v.22, p.157-172, 1995.

IVANAUSKAS, N. M.; MONTEIRO, R.; RODRIGUES, R. R. Estrutura de um trecho de floresta Amazônica na bacia do alto rio Xingu. Acta Amazônica, v.34, n.2, p.275-299, 2004.

JOLY, C. A. et al. Evolution of the Brazilian phytogeography classification systems: implications for biodiversity conservation.

Ciência e Cultura Journal of Brazilian Association for the Advancement of Science, v.51, n.5/6, p.331 348,1999

JUNK, W. J. Wetlands of tropical South America. In: WHIGHAM, D.; HEJNV, S.; DYKVJOVE, D. (Eds). Wetlands of the world. Dordrecht: Kluwer Academic Publishers, 1993. p.679-739.
KUNZ, S. H. et al. Estrutura fitossociológica de um trecho de Floresta Estacional Perenifólia Bacia do rio das Pacas, Querência, MT. Cerne, v.16, n.2, p.115-122, 2010.

LAURENCE, W. F. et al. The future of Brazilian Amazon. Science, v.291, p.438-439, 2001.

LIU, W. T. H. Aplicações de sensoriamento remoto. Campo Grande: UNIDERP, 2007. $908 \mathrm{p}$.

LOVEJOY, T. E. Amazonian forest degradation and fragmentation: implications for biodiversity conservation. In: HALL, A. (Ed.). Amazonia at the crossroads. London: Institute of Latin American Studies, University of London, 2000. p.41-57.

MAEDA, E. E.; FORMAGGIO, A. R.; SHIMABUKURO, Y. E. Análise histórica das transformações da Floresta Amazônica em áreas agrícolas na Bacia do Rio Suia-Miçu. Sociedade e Natureza, v.20, n.1, 2008. Disponível em: $<$ http://www.scielo.br/scielo.php?script=sci_ arttext\&pid=S1982-45132008000100001\&lng= pt\&nrm=iso $>$. Acesso em: 22 mar.2010.

MARTINS, S. V. Restauração florestal em Áreas de Preservação Permanentes e Reserva Legal. Viçosa, MG: Centro de Produções Técnicas, 2010. v.1.316p.

MARTINS, S. V. et al . Floristic composition of two wetland forests in Araguaian Plain, State of Tocantins, Brazil, and comparison with other areas. Revista Árvore, v.32, n.1, 2008 . Disponível em $<$ http://www.scielo.br/scielo.php?script=sci_ arttext\&pid=S0100-67622008000100015\&lng=pt\&nrm= iso >. Acesso em: 23 mar. 2010.

MARTINEZ, L.; FIEDLER, N. C.; LUCATELLI, G. J. Análise das relações entre desflorestamentos e focos de calor. Estudo de caso nos municípios de Altamira e São Félix do Xingu, no estado do Pará. Revista Árvore, v.31, n.4, p.695-702, 2007.

MENEZES, M. L. P. Parque Indígena do Xingu: a construção de um território estatal. Campinas: UNICAMP, 1999. 404p.

MORTON, D. C. et al. Cropland expansion changes deforestation dynamics in the southern Brazilian Amazon. Proceedings of the National Academy of Sciences, v.39, n.103, p.14637-14641, 2006.

Revista Árvore, Viçosa-MG, v.36, n.3, p.489-498, 2012 
PRANCE, G. T. Notes on the vegetation of Amazonia III. The terminology of amazonian forest types subject to inundation. Brittonia, v.31, n.1, p.26-38, 1979.

RICHARDSON, C. J. Ecological functions and human values in wetlands: a framework for assessing forestry impacts. Wetlands, v.14, n.1, p.1-9, 1994.

RIZZINI, C. T. Tratado de Fitogeografia do Brasil. Rio de Janeiro: Âmbito Cultural Edições, 1992. 788p.

ROSSETE, A. N. Caracterização e zoneamento ambiental do Município de Querência - MT. 2008. 108f. Tese (Doutorado em Ecologia e Recursos Naturais) Centro de Ciências da Saúde e Biológicas, Universidade Federal de São Carlos, São Carlos, 2008.

SANCHES, R. A.; VILLAS-BÔAS, A. Os formadores do rio Xingu: desafios para a presevação e gestão ambiental. In: BENSUSAN, N. (Org.) Seria melhor mandar ladrilhar? Biodiversidade como, para que, por quê. Brasília: Instituto Socioambiental, Universidade de Brasília, 2008. p.303-316.
SEEGER, A. Nature and society in Central Brazil. The Suya Indians of Mato Grosso. Cambridge: Harvard University Press, 1981. 278p.

SOARES-FILHO, B. S. et al. Modelling conservation in the Amazon basin. Nature, v.440, n.23, p.520-523, 2006.

STEFANELLO, D. et al. Síndromes de dispersão de diásporos das espécies de trechos de vegetação ciliar do rio das Pacas, Querência - MT. Acta Amazônica, v.40, n.1, p.141-150, 2010.

STEFANELLO, D. Florística, estrutura e dispersão de sementes de três trechos de floresta estacional perenifólia ribeirinha na bacia hidrográfica do rio das Pacas, Querência - MT. 2008. 83f. Dissertação (Mestrado em Ciências Florestais) - Universidade Federal de Viçosa, Viçosa, MG, 2008.

TOCKNER, K.; STANFORD, J. A. Riverine flood plains: present state and future trends.

Environmental Conservation, v.29, p.308330, 2002.

TURNER, K. Economics and wetland management. Ambio, v.20, n.2, p.59-63, 1991. 